\title{
Accessing Tertiary Education and Experiences of Non- Commissioned Officers in the Military: A Gender Perspective of Selected Ndola Army Based Units
}

\author{
Ivy Nawa Akabondo, John Mwitumwa Matakala, Annie Namakando-Phiri, Mubiana \\ Macwan'gi \\ Department of Gender Studies, University of Zambia, Lusaka; Zambia
}

\begin{abstract}
*Corresponding Authors: John Mwitumwa Matakala, Department of Gender Studies, University of
\end{abstract} Zambia, Lusaka; Zambia

\begin{abstract}
The study was designed to explore and understand the lived experiences of the Non-Commissioned officers in the Army in relation to accessing tertiary education in Ndola Based Army Units from a Gender perspective. The motivation behind this study was that despite measures put in place to promote tertiary education, it was not known how the levels of participation in tertiary education were in the military by the NCOs in relation to their respective sex. The objectives of the study were: (1). to assess the participation of the NCOs with regard to tertiary education in the Army, (2). to determine the causes of low participation in accessing tertiary education by the NCOs in the Army, and (3). to investigate the strategies put in place in accessing tertiary education by the NCOs in the Army. A mixed methods research design which combined qualitative and quantitative technique was used in this study. The target sample comprised of noncommissioned officers, the command, chief clerks and education warrant officers.
\end{abstract}

Purposive sampling, Simple random sampling were used to select 100 male and female, participants for the study. In-depth interviews and focus group discussion were used to collect primary data. Qualitative data were analyzed thematically through the identification of themes that emerged from the data. While descriptive statistics were used analyze quantitative data. The findings of the study revealed that access to tertiary education by the NCOs was low. Evidence shows that the number of NCOs who acquire tertiary education is less in numbers as compared to those who don't receive the training at all. For example, out of the strength of 645 men and women in uniform in one of the selected units in Ndola, only 135 have had access to tertiary education from 2000-2017.

Access to tertiary education was also lower for the female soldiers as compared to their male counterparts. The lower access to tertiary education by female soldiers was attributed to lower levels of education as they did not meet the entry requirements for tertiary education, coupled with the negative attitudes by commanders in preference to military courses especially at section level. Furthermore, the study found that there are regulatory measures put in place by the Army in order to curb the low accessibility to tertiary education such as self-sponsorship Consent Form. The same form was also discovered to be a hindrance in accessing tertiary education due to the stiff conditions attached to it. It learnt that the majority of NCOs are shunning from signing the document. It was also discovered that the Army only grants 6 months paid leave. In the event that the course exceeding six (06) months, the applicant shall be deemed to be on unpaid study leave. This means that the candidate will go without pay for the remaining of the course of study. This in itself is a hindrance as the majority of the NCOs cannot afford to pay the tuition fees for themselves. Especially considering that most of the programmers in higher education run for a period of more than one year. In the quest to allow soldiers to further their studies the Army has also signed a Mou with the University of Zambia and Nkrumah University. These institutions do reserve some slots for soldiers and officers who meet the desired entry requirements every year.

Keywords: Accessing Tertiary Education, Non-Commissioned Officers.

\section{INTRODUCTION}

\subsection{Background to the Study}

Globally, Access to tertiary education or higher education in different working environments has become a major gender source of concern. Available evidence indicates that the junior workforce, 
especially women in both public and private organizations, the Army inclusive have challenges in accessing higher Education (ILO, 2010).

In a survey conducted in some public and private organizations in the United States of America around Seattle and New York areait was established that access to tertiary education by the junior workforce is still a challenge in both private and public organizations including the military organizations by the US Department of Education (2011).

Reading through empirical literature, show that there are various research studies that have reacted to the global concern with respect to accessing of tertiary education in military communities. Most of these studies are however more inclined to the global level in particular the United States of American Armies.

A research study in America focused on the impact of military experiences of veterans with regard to higher education. It focused on both those that were serving and not serving. The study was conducted Among the united states of American soldiers.Jeffrey (2015).

Another study was conducted in America but with a focus on the exploration of higher academic success of military student veterans in higher education from those that were serving in the American Armies including those that had stopped Claire (2015).

An interaction with empirical literature indicates that it appears no studies at regional level in Africa. However, there is a research study at local level in Zambia that like the several aforementioned studies reacted to the global concerns on accessing of tertiary or higher education.

A research study conducted in Zambia on higher or tertiary education focused on the aspirations of the commissioned ranks.

From the afore mentioned research studies it appears most of them concentrated on the veteran commissioned officer and non-commissioned soldiers that have served many years and are about to retire as indicated by the studies in the American Armies.

Furthermore, the local study in Zambia focused on the young commissioned ranks with a small service in the military.

Therefore, the identified theoretical problem is that it appears that no study has looked at accessing of tertiary education with regard to the soldiers in general by capturing both the long service and short service personnel. Usually the short service is young and they have not served for many years.

This is a knowledge gap that this study intended to fill in by the end of the inquiry.

The motivation behind this study was to ensure the solution caters for the young and veteran soldiers regardless of sex so as to ensure gender equality.

\subsection{Statement of the Problem}

Accessing Tertiary Education and Experiences of Non-Commissioned Officers in The Military from a Gender Perspective of Selected has not been done in Zambia. This is with specific reference to selected units in Ndola.

This is a compelling knowledge gap.

\subsection{General Objective}

To explore and understand the lived experiences of the non-commissioned officers in the Zambia Army in relation to accessing tertiary education from a gender perspective.

\subsection{Specific Objectives To:}

- To assess the extent of participation by sex and rank of non-commissioned officers with regard to tertiary education in the Army.

- To understand the reasons for low participation in accessing tertiary education by noncommissioned officers in the Army.

- To establish the strategies put in place in accessing tertiary education by non-commissioned officers in the Army. 


\subsection{Research Questions}

- What is the extent of participation by sex and rank for non-commissioned officers with regard to access to tertiary education in the Army?

- What are the reasons for low participation in accessing tertiary education by noncommissioned officers in the Army?

- What are the strategies put in place to promote accessibility to tertiary education by noncommissioned officers in the Army?

\subsection{Significance of the Study}

This study is ground breaking because it will concentrate on the soldiers with respect to accessing of tertiary education because it has not been done as a way of not only contributing knowledge to the discipline of gender studies at the University of Zambia but will also inform policy. The results and recommendations will further be forwarded to policy makers for practical implementation by the Military authorities.

It is also hoped that it will act as a stepping stone for further research apart from adding knowledge.

\subsection{Ethical Consideration}

Ethical clearance was obtained from the ethics Committee of the University of Zambia. Thereafter, dual permission was sought from military authorities and the actual participants.

\subsection{Definition of Terms}

- Participation in tertiary education: those soldiers who are able to have access to go for tertiary education.

- Other Rank- A person serving in the Army who is not Commissioned also referred to as non- commissioned officer.

\subsection{Purpose Statement}

The purpose of this two phased Sequential Mixed Methods inquiry was explore and understand the lived experiences of the non-commissioned officers in the Zambia Army in relation to accessing tertiary education from a gender perspective.

In the first phase the Quantitative question was meant to assess the extent of participation by sex and rank of non-commissioned officers with regard to tertiary education in the Army. This was meant to avail some special constructs leading to the buildup for the second phase of the qualitative phase on which this inquiry foundation rests. Therefore, information from this first phase will be explored further in a second qualitative phase.

In the second phase Qualitative in-depth and Focus Group interviews were used to probe quantitative significant results by exploring all the aspects of the central phenomenon that is aforementioned on few selected participants from selected military bases in Ndola, Zambia.

The reason for the follow up with the qualitative phase was to explore and Understand the lived experiences of the participants in relation to the central phenomenon under investigation as a way of explaining the quantitative results.

The whole idea was to come up with mitigation measures of improving the situation with respect to access of tertiary education in the military.

\section{MeThOdology}

A qualitative research approach was used grounded in the philosophy of Interpretivism in order to understand the experiences and interpretations of accessing tertiary education from a gendered perception among soldiers. The research design that was used was the Embedded Existential Phenomenology that is mostly inclined to the qualitative approach but embracing quantitative constructs that build on the lived experiences of the participants Egaden (2012). 


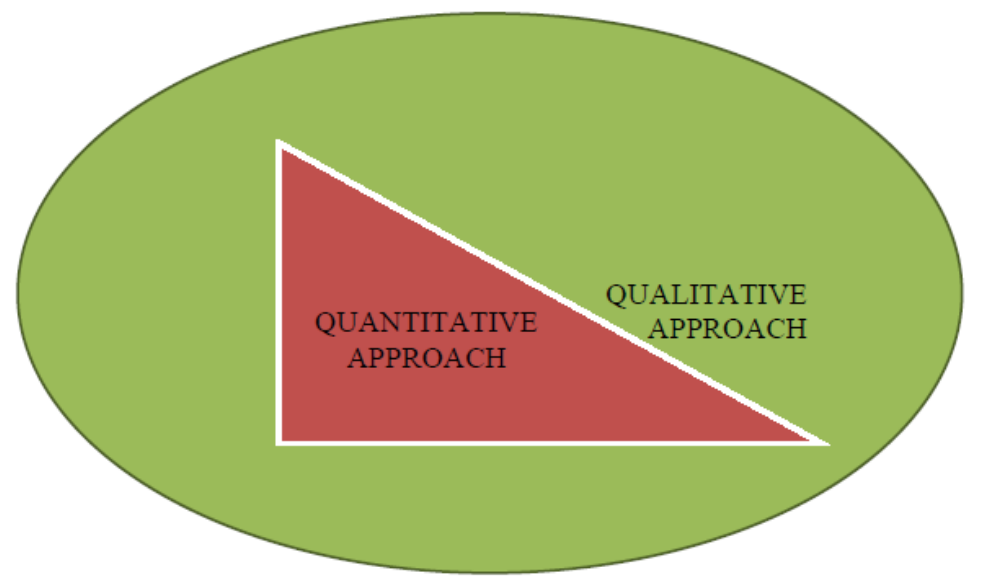

Figure1. Embedded Existential Phenomenology Research (Mixed) Design

Adapted from Egaden: 2012

The study was conducted on the copper belt part of Zambia in particular Ndola from selected military bases based on experiences on the accessing of tertiary education with respect to soldiers. Simple Random Sampling were used to come up with the desired sample size of 100 respondents. From the main sample size generated, the study went ahead to use the judgmental selection in order to come up with few soldiers to provide answers to the rest of the research questions.

The resultant data were collected through the self-administered questionnaires, in-depth and focus group interview guides from the respondents and the participants who are the soldiers. Data collection procedure began with the pretest, prescribed interview/Questionnaire process and sequential strategy actual data collection.

Pretest. Before the actual data collection, self-administered questionnaires, the interview guides and focus group discussion guides were subjected to prior data collection so as to standardize the research instruments so that they are able to collect the desired information.

Interview process. The participants were first greeted by the researcher. For the questionnaire it was indirect in that it was not face to face but enshrined in the document while for the interviews it was face to face. They were later told the purpose of the study both directly and indirectly and consent was gotten from them before the inquiry. They were also assured of confidentiality and that they had a right to pull out at any time they felt uncomfortable as it was there right before commencement of the giving answers to the questionnaire or interview.

They were then thanked face to face in the interview and also on the self-administered questionnaires.

Sequential explanatory strategy. Was used to collect the data because the objectives were followed chronologically beginning with the quantitative objective and ending with qualitative objectives Creswell (2009).

The findings were thermalized chronologically in line with the first objective which was to assess the extent of participation by sex and rank of non-commissioned officers with regard to tertiary education in the Army, to understand the reasons for low participation in accessing tertiary education by noncommissioned officers in the Army and to establish the strategies put in place in accessing tertiary education by non-commissioned officers in the Army.

The data were analyzed by the use of the Statistical Package for Social Sciences (SPSS).The Quantitative software was opened and immediately the variable view window was displayed showing the following name, type, width, decimals, label, values, missing, columns, alignment, measure and role.

Information from the self-administered questionnaire were entered in these rows and columns. Once all the variables were entered the next stage was to go to the TAB on top and click on analyze. This was followed by proceeding to the descriptive statistics which gave a direction to frequencies which brought the options of graphs and pie charts from which the study selected from. The information was the exported to word. 
The qualitative data were analyzed by the use of the phenomenological data analysis by reducing the large amounts of data by transcribing each script in order to come up with the themes and sub themes of the inquiry.

Furthermore, issues of reliability on the first quantitative research question were ensured by pretesting the self-administered questionnaire so that it was able to come up with information that it was supposed to gather. The data collected was then said to be validated Msabila and Nalaila (2013).

Furthermore, under qualitative approach the issues of trustworthiness were achieved through Guba's four trustworthy strategy of credibility, dependability, transferability and Confirmability. It falls under the volunteristic axiology which looks at ethics and aesthetics which looks at the value of the study academically Guba and Lincoln (1994).

Credibility. Was ensured by choosing of the correct research design or plan which was the existential phenomenology hence the data is correct and is acceptable academically.

Dependability. Was done through standardizing the research instruments so that they get the desired information hence the data is correct and is acceptable academically.

Conformability. Was done by ensuring the phenomenological reduction or 'epoche' or bracketing of pre conceived ideas through listening and taking the information as it comes.

Transferability. Was done through the afore mentioned in that the study has the capacity of being contextualized with other studies so as to come up with similarities which can lead to identification of gaps by other studies.

\section{RESUlTS \& DisCUSSION}

\subsection{What is the Extent of Participation by Sex and Rank for Non-Commissioned Officers with Regard to Access to Tertiary Education in the Army?}

\subsubsection{Contextualized Similarities with Other Empirical Studies}

Table4.3.2. Civil Courses (Tertiary Education Accessibility by Sex)

\begin{tabular}{|c|c|c|c|c|c|}
\hline \multicolumn{2}{|c|}{ Strength } & \multicolumn{2}{|c|}{ Strength } & \multicolumn{2}{|c|}{ Strength } \\
\hline \multicolumn{2}{|c|}{$\begin{array}{l}\text { Musafya } \\
\text { Military } \\
\text { Base (Pseudo Name) }\end{array}$} & \multicolumn{2}{|c|}{$\begin{array}{l}\text { Ntobalento } \\
\text { Military } \\
\text { Base (Pseudo Name) }\end{array}$} & \multicolumn{2}{|c|}{$\begin{array}{l}\text { Mutobelibwe } \\
\text { Military } \\
\text { Base (Pseudo Name) } \\
\end{array}$} \\
\hline $\mathrm{F}$ & $\mathrm{M}$ & $\mathrm{F}$ & $\mathrm{M}$ & $\mathrm{F}$ & $\mathrm{M}$ \\
\hline $2 / 8$ & $17 / 522$ & $3 / 185$ & $7 / 291$ & $30 / 150$ & $75 / 495$ \\
\hline $0.4 \%$ & $3.2 \%$ & $0.6 \%$ & $1.5 \%$ & $4.6 \%$ & $11.6 \%$ \\
\hline
\end{tabular}

Answers to the self-administered questionnaire show the following information shown with respect to participation in tertiary education:

Key

1. Females attended civil courses $\quad 5.6 \%$

2. Males attended civil courses $\quad 16.3 \%$

3. Females/males not attended civil courses $\quad 78.1 \%$

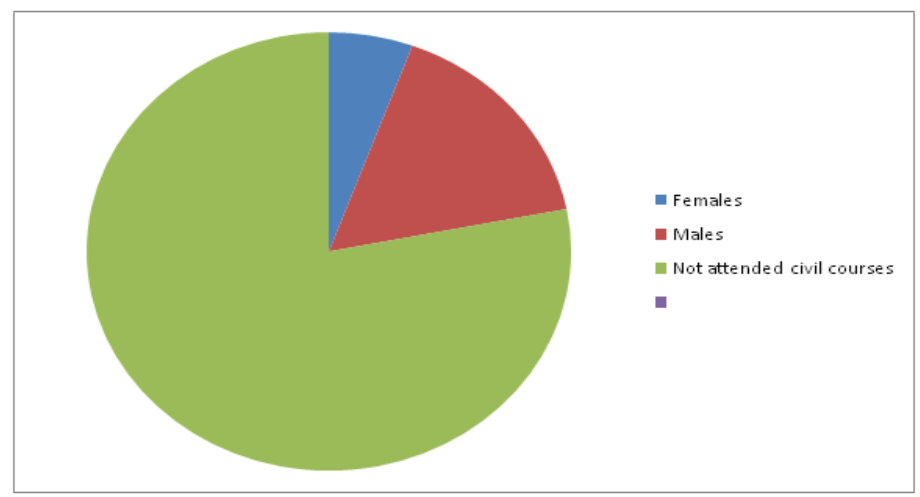

Figure2. Pie chart showing participation rates from Ndola Army-based units by sex-other ranks. 
Key

1. Females attended civil courses $\quad 5.6 \%$

2. Males attended civil courses $\quad 16.3 \%$

3. Females/males not attended civil courses $\quad 78.1 \%$

Figure 1 Pie chart showing participation rates from Ndola army-based unit by gender-other officers

From Soldiers for the three military bases where data was collected, their responses were put into a pie chart to test these parameters. After computation the following was discovered:

Participation rates stood at $16.3 \%$ for males and $5.6 \%$ for females. These data were for NonCommissioned Officers only; this is as dictated by the research topic. The analysis further revealed that $78.1 \%$ did not attend civil courses at all. This data clearly shows how low the female participation is compared to that of males.

Although the study findings are similar to the study of Mizinga (2004) which sets precedence to this inquiry noticeably is the fact that it's main focus was the junior officers in the Zambia Army. It appears the reason has to do with limited resources.

\subsubsection{Dissimilarity With Other Studies (Contextualised)}

It appears no study found a low participation of soldiers therefore this is new knowledge.

\subsection{What are the Reasons for Low Participation in Accessing Tertiary Education by Non- Commissioned Officers in the Army?}

\subsubsection{Contextualized Similarities with Other Empirical Studies}

\begin{tabular}{|c|c|}
\hline $\begin{array}{l}\text { Empirical Findings on reasons for low } \\
\text { participation in accessing tertiary education by } \\
\text { non-commissioned ranks in the Army }\end{array}$ & $\begin{array}{l}\text { Research Findings on the reasons for low } \\
\text { participation in accessing tertiary education by } \\
\text { noncommissioned ranks in this Study }\end{array}$ \\
\hline $\begin{array}{l}\text { - The findings from empirical literature show the } \\
\text { following reasons for low participation in } \\
\text { accessing tertiary education by noncommissioned } \\
\text { ranks; } \\
\text { - Global Perspective. } \\
\text {-It was established that accessing tertiary education } \\
\text { was low for both commissioned and } \\
\text { noncommissioned ranks in the Usa Armies due to } \\
\text { military operations both locally and abroad } \\
\text { Jeffrey (2015) and Claire (2015). } \\
\text { Local Perspective } \\
\text {-It was established that they attend } \\
\text { Military operations both locally and } \\
\text { Abroad. }\end{array}$ & $\begin{array}{l}\text { - The findings of this study are in agreement with } \\
\text { the other studies on the low participation in } \\
\text { accessing tertiary education. } \\
\text { - The findings of this study are similar because it } \\
\text { appears there is universality in the way military } \\
\text { operations are done in the military with regard } \\
\text { to the united nations peace keeping operations } \\
\text { and internal operations the service personnel } \\
\text { busy at global level. } \\
\text { - Whether itis at global level therefore the } \\
\text { situation is similar. }\end{array}$ \\
\hline
\end{tabular}

Source: Field Data (2017) and Empirical Literature

This is what a male Staff Sergeant had to say when asked what the reasons for low participation with regard to accessing tertiary education are;

'Madam 'meaning the researcher' I find it difficult to access tertiary because am

Always on the move I don't stay in base for a long time. When going for the

United nations peace keeping operations I had to go for training in lusaka for

Pre-deployment training one year plus another year abroad..................."

This is what a female Staff Sergeant had to say when asked what the reasons for low participation with regard to accessing tertiary education are;

"Madam 'meaning the researcher' I find it difficult together with my fellow

Rank mates because we get committed with local operations were we stay for 
More than a year coming back the talk of a military course it is rough......"

\subsubsection{Dissimilarity with Other Studies (Contextualised)}

The study established that the other reasons for the low participation in the accessing of tertiary education is alluded to Commanders at different levels encouraging soldiers to concentrate on the military courses which had the capacity to enhance their military career progression. Additionally, another finding that the study established was that most of the female soldiers had grade twelve certificates that did not reach the cut of points that did not match those in higher institutions in order to be admitted.

This is what a male Sergeant had to say when asked what the reasons for low participation with regard to accessing tertiary education are;

\section{"Madam 'meaning the researcher' I can't access tertiary level of education}

With Public institutions because my Commander asks me and my other

Colleagues to concentrate on military courses at the army military schools.

This makes it difficult for me to access the higher education .................."

This is what a female Sergeant had to say when asked what the reasons for low participation with regard to accessing tertiary education are;

"Madam 'meaning the researcher'I would like to go for a civil course

At any higher learning institution but the only hic up is that my grade

Twelve certificate which does not meet the minimum entry requirement

In most ..”

The findings on the issue of preference for military training to tertiary education is new knowledge. It appears a review of literature shows that none of the studies came up with this finding. Therefore, this is an addition of new knowledge that, was not known but is now known.

The reason for this difference is alluded to the fact that different Armies have different priorities at global level which vary.

In addition to the finding above the other new knowledge that was different from other studies was with regard to the lower grade twelve grades for female soldiers which made it difficult for them to access entry in higher education. Again it appears from the reviewed literature that no studies came up with this finding hence new knowledge.

The reason for this difference in finding, with other studies can be alluded to the recruitment criteria which differs in terms of joining the military career. Other Armies pick those with higher O Levels while others pick those with low O Levels.

\subsection{What are the Strategies Put in Place to Curb the Low Accessibility to Tertiary Education of the Junior Workforce?}

\subsubsection{Contextualised Similarities with Other Empirical Studies}

\begin{tabular}{|l|l|}
\hline $\begin{array}{l}\text { Empirical Findings on the strategies put in } \\
\text { place to curb the low accessibility to tertiary } \\
\text { education of the junior workforce }\end{array}$ & $\begin{array}{l}\text { Research Findings on the strategies put in place to } \\
\text { curb the low accessibility to tertiary education of } \\
\text { the junior }\end{array}$ \\
\hline $\begin{array}{l}\text { The findings from empirical literature show } \\
\text { the following responses on the strategies put }\end{array}$ & $\begin{array}{l}\text { The findings of this study are in agreement with } \\
\text { the other studies in terms of strategies put in place } \\
\text { to curb the low accessibility to tertiary education }\end{array}$ \\
$\begin{array}{l}\text { in place to curb low accessibility to tertiary } \\
\text { education of the junior workforce or the } \\
\text { noncommissioned ranks are shown hereunder; } \\
\begin{array}{l}\text { Global Perspective. } \\
\text {-It was established that accessing of tertiary } \\
\text { education was backed by military strategies } \\
\text { that involved entering into Memorandum of }\end{array}\end{array}$ \\
\hline
\end{tabular}


Understanding (MOU) with civilian institution to undertake both postgraduate and undergraduate studies by military personnel Jeffrey (2015) and Claire (2015).

Local Perspective

-It was established that the military has

Entered into an agreement with the

University of Zambia and Nkrumah

University for capacity building of the Military personnel.
- Whether itis at global level therefore the situation is similar.

Source: Field Data (2017) and Empirical Literature

This is what a male Staff Sergeant had to say when asked what the available strategic measures of curbing with low accessing of tertiary education were;

"Madam 'meaning the researcher' the Army has engaged into a Memorandum

Of Understanding with the University of Zambia through the School of Humanities

And social sciences in order for commissioned ranks to access the Master of

Defense and Security Studies. Further it has also solicited for four places at

Nkrumah were both commissioned and noncommissioned ranks are selected

Every year.....

\subsubsection{Dissimilarity with Other Studies (Contextualised)}

The study established that the other responses on the strategies put in place to curb the low accessibility of tertiary education show that the military authorities have come up with the idea of allowing personnel to pursue those studies for a year as the maximum only.

This is what a female Staff Sergeant had to say when asked what the available strategic measures of curbing with low accessing of tertiary education were;

"I know that one of the strategies of ensuring access to tertiary education is by

The coming up with a deliberate policy that personnel are given a one year to

Attend to tertiary education. However, disadvantage is for courses that go over

A period of one year then those may be removed from the payroll

The last finding is new knowledge because it appears none of the reviewed literature came up with the aforementioned finding.

The reason for the finding is alluded to the fact that each Army has its own way of administering its personnel when it comes to accessing tertiary education.

\section{CONCLUSiON}

The conclusion of the whole matter is that this study will avail information to the policy makers for policy implementation from the findings of the out lined research questions.

- What is the extent of participation by sex and rank for non-commissioned officers with regard to access to tertiary education in the Army?

- What are the reasons for low participation in accessing tertiary education by noncommissioned officers in the Army?

- What are the strategies put in place to promote accessibility to tertiary education by noncommissioned officers in the Army?

The findings for the research question one show that there is a low participation in tertiary education for both male and female soldiers. What also came out is that the accessibility for female soldiers was lower than that of the male soldiers according to the preliminary findings. 
The findings for the research question two show that their military engagements result in the failure to attend to tertiary education.

The findings for the research question three show that the military is engaged in a memorandum of understanding with high learning institutions.

Owing to this conclusion there is a need of proposing of recommendations based on the researcher perspective to mitigate the problem so as to inform policy.

\section{RECOMMENDATIONS}

In view of the important role education that is attached to the human resource development there is a need for conceited efforts by stake holders such as the ministry of defense and the army through the education directorate to implement the proposed recommendations of this study. The findings of this study inform the ministry of defense in Zambia to find lasting policy that will enhance the low access of tertiary education in the country, that will not only better the military in Zambia but also other Armies, globally.

This should be done in the most effective and sufficient manner as suggested below by the researcher. Presented below are the proposed recommendations.

- The ministry of defense (Mod) through the Director of Education should enter into a memorandum of understanding (Mou) with many institutions of learning for some slots that should be left for the military personnel of the noncommissioned rank and further allow those that have the resources for self-sponsorship.

- The Army should consider coming up with General Certificate of Education in the main military bases. This must have afternoon classes in order to enhance development for the female soldiers and their academic so that they are able to meet the cutoff point in tertiary education admission.

- The Army should come up with a rotation list of events for military operations/courses and civil courses so that there is time for all the events in the military cycle of a junior soldier in the non commissioned ranks.

\subsection{Recommendations for Further Studies}

It is recommended that that a future study must consider undertaking the development of a participatory conducive approach for accessing of tertiary education among soldiers through the use of social or emancipation action principles with the usage of the interprativist participatory approach and the interprativist emancipation phenomenology Egaden (2012).

This process must be considered for Doctoral Studies being an action research oriented process.

Social Action: Is a two phased inquiry which begins by finding answers through participant experiences from prerequisite standardized research questions, after which the researcher develops an action agenda for change, which is used for establishing conducive ways based on victim ideas under his guidance.

Participatory approach: is a process of getting conducive strategies for accessing of tertiary education from participants under the guidance of the researcher leading to a given research output.

This can be achieved through detailed process below;

Process of Developing a Participatory Conducive Approach for Accessing Tertiary Education among Soldiers in Zambia, Using Social /Emancipation Action Principles.

\section{GENERATING FORMATIVE INORMATION (PHASE ONE)}

\{Pre Requisite Standardasised information based on Soldiers Perceptions\}

- The reason is because there is no conducive approach for easy access of tertiary education for soldiers in Zambia.

- The Pre Requisite standardized questions from Soldiers perceptions are;

a. Identification of gaps in the Programs and Policies of accessing tertiary education.

b. Contributing factorsof challenges in the access of tertiary education among soldiers in Zambia.

c. Classification of challenges in accessing tertiary among soldiers in Zambia. 


\section{DEVELOPING THE PARTICIPATORY CONDUCIVE APPROACH (PHASE TWO)}

- Selection criteria for participants and their areas of origin to engage in the group Emancipation

a. All the soldiers that have been victims of having failed to access tertiary education will be purposively selected to form part of the group.

b. They must have been denied access to tertiary education not less than three times.

- Eliciting of conducive ways of accessing tertiary education from the emancipation groups (Corroboration)

c. An Action Agenda for Change in form of a predetermined question by the researcher is used to elicit the conducive ways from the group under the guidance of the researcher who also takes down the notes.

- Analysis and Interpretation of input from the participants

a. Upon the completion of the collection of the conducive ways of teaching and learning of the subject from the group the researcher proceeds to give meaning to the input.

- Validation and Consensus building with the group

a. After having given meaning to the conducive ways of the group the researcher returns back the information back to the participants for the final adoption.

b. The participatory conducive approach is given a formal identification name.

Adapted from Egaden (2012).

\section{ACKNOWLEDGEMENT}

I wish to thank my supervisor Dr Anne Namakando-Phiri (Col) for the guidance in this research thesis. I further thank and all the Lecturers in the Department of Gender Studies for their advice.

\section{REFERENCES}

[1] Bless, C and Achola, P. (2001). Fundamentals of Social Research Methods, Pauline Publishers, Nairobi.

[2] Creswell, J.W. (2007). Qualitative Inquiry and Research Designs: Choosing Among Five Approaches, $2^{\text {nd }}$ ed. Sage Publishers, London.

[3] Creswell, J.W. (2009). Research design: Qualitative, Quantities and Mixed methods Approaches, Sage Publishers, New Delhi.

[4] Cohen, A. (2001). Review of Literature: Responses to "Empirical and Hermeneutic Approaches to Phenomological research in Psychology, a Comparison" Gestalt, 5 (2) retrieved from http:www.ggej.org/5-2/reviewlit.html.

[5] Jeffrey, D.S (2015). The impact of military experiences on higher education of veterans, Illinous State University publishers.

[6] Egaden, C.L. (2012). Participatory Action/Toolkit Procedure using Future Search Research: A Modern Thought for Doctoral and Post Doctoral Students, Sage Publications, London.

[7] Giorgi, A e' tal. (1985), Phenomenology and Psychological Research Duquesne University Press, Pittsburg.

[8] Hart, C. (2013). Doing a Literature Review: Release the Social Science imagination, Sage Publications, London.

[9] Holloway I. and Wheeler S. (1996). Qualitative Research for Nurses, Hartinolis Ltd, London.

[10] Moustakas, C. (1994) Phenomenological Research Methods,sage publications, London.

[11] Mizinga, J. S. (2004) Aspirations for higher education among commissioned officers in Zambia, University of Zambia publishers (Dissertation), Lusaka.

[12] Semer, C. (2015) Exploring the higher academic success of military student veterans in higher education, University of Toledo publishers (PhD Thesis), Toledo.

\section{AUTHOR'S BIOGRAPHY}

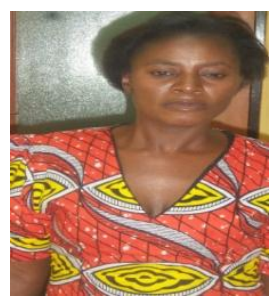

Ivy Nawa Akabondo is a Master of Art in Gender Studies? At the University of Zambia. She Is the Main Researcher in this Inquiry. She has a Bachelor of Arts Degree in History and Religious Studies from the University of Zambia. 


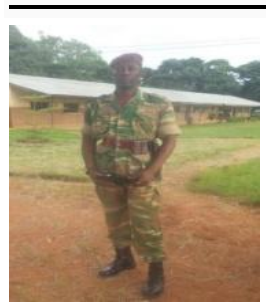

John Mwitumwa Matakala is a Doctor of Philosophy Research Fellow in Gender Studies. At the University Of Zambia. He is a Researcher in this inquiry. He is also Special Force Soldier in the Commando Unit.

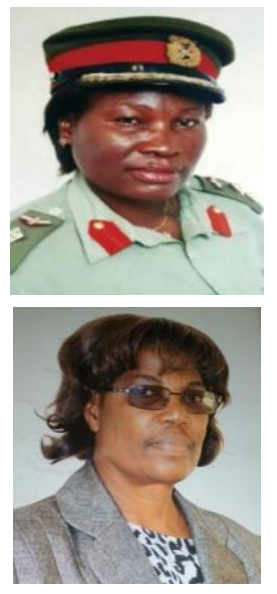

Dr. Annie Namakando -Phiri (Col) The Doctor of Public Healthy /Epidemiology/ Gender. She Is Also A Senior Retired Army Officer. Was a Head of Department - 2013 To 2016. At The University Of Zambia. She is a the Main Supervisor in This Research Inquiry and Phenomenological Advisor in This Inquiry Senior Lecturer/Researcher - Department Of Gender Studies

Prof. Mubiana Macwan'gi, the Professor of Public Health The Principal Supervisor of the Study. Was the Institute of Economic and Social Research Director - 2010 to 2016 at the University of Zambia. She is a Research and Innovation Advisor in this Inquiry. Senior Lecturer/Researcher - Department of Gender Studies

Citation: John Mwitumwa Matakala. "Accessing Tertiary Education and Experiences of Non-Commissioned Officers in the Military: A Gender Perspective of Selected Ndola Army Based Units" International Journal of Humanities Social Sciences and Education (IJHSSE), vol 5, no.9, 2018, pp. 57-67. doi: http://dx.doi.org/10. 20 431/2349-0381.0509010.

Copyright: (C) 2018 Authors. This is an open-access article distributed under the terms of the Creative Commons Attribution License, which permits unrestricted use, distribution, and reproduction in any medium, provided the original author and source are credited. 